\title{
From the Associate Editor of Electronic Publications: "Ritual Technology"
}

\author{
Pete Smith \\ University of Texas--Arlington
}
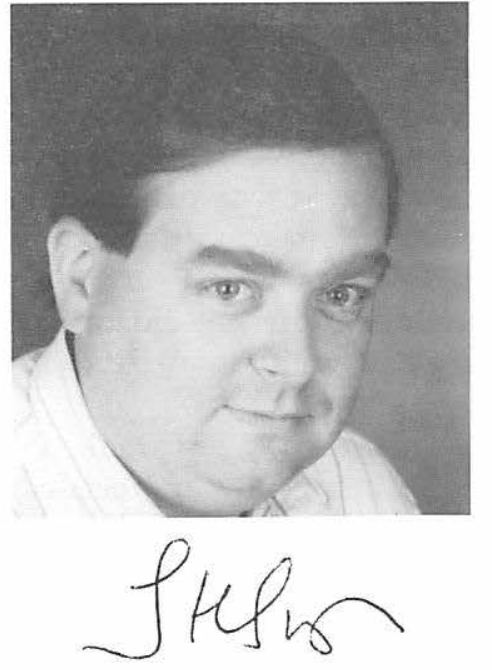

Last night at home, I spent more than an hour listening and relistening to a recently-resuscitated feature on the Web pages of Deutsche Welle Radio-Deutsch lernen mit Nachrichten - the daily news in German, spoken at a controlled pace for language learners. This is a source of pedagogically-prepared language and current events that I have come to depend upon daily; it has become a ritual for me. I am a teacher of Russian, but Istrive regularly to maintain my rapidly-decaying skills in German as well.

My dependence on Internet media for language maintenance came about quite by accident, as the number of international broadcasters on the 'net skyrocketed in the past several years. More importantly, this experience has opened my eyes to the role of digital media in life-long language learning.

As IALL members, we all appreciate the importance of electronic sources of language and culture in formal instruction. Resources such as the Internet now even allow us to deliver, in whole or in part, college and university coursework. Department of Education statistics recently released tell us that, in 1998, more than 1.6 million post-secondary students nationwide enrolled in more than 54,000 on-line classes.

But as a language teacher, I must admit that I am increasingly less interested in formal instruction, and correspondingly more interested in what follows the classroom experience. As I have written in these pages before, I believe that too many language students leave our classrooms without the skills, the motivation, or the inspiration to make a non-native language part of their daily existence. I hold steadfastly to the principle that life-long study and appreciation of a foreign language can change lives. It did for so for many of us.

We are richer today than we have ever been in the resources to foster and support daily contact with a non-native 
language, primarily due to the Internet revolution. I remember all too well my time as a graduate student of Russian in the early 1980 's. So few media sources were available to us then that I marvel at how I somehow managed to stay in contact with the language at all. A good part of my post-graduate career was spent hunched over a shortwave radio, listening for the few sources of Russian I could find. Now, with the advent of Internet radio, I am awash in Russian, German, and nearly other any language I can think of.

Now, how do we as teachers leverage this new-found wealth? I would argue that our vistas must be broader than the first semesters of classroom study. We need to focus not on the language learner, but rather on the life-long language learner. Inow attempt, in every class period I teach, to share at least one Internet-based source with my students. But it is not that simple; I also work to instill in them the motivation and discipline for daily, life-long language appreciation. It is not enough simply to show off a new on-line newspaper or to demonstrate an exciting Internet broadcast. I want to motivate and inspire learners to start and to continue with the disciplined, daily contact with a foreign language that will make a difference. Amidst our increasingly busy lives, it is no small feat to find the discipline to work on a task for 15 minutes/day, or even for 30 minutes, each and every day, every day, without fail. It is a matter of ritual.

A central tenet I hold about language study is: to make a foreign language part of you and to more fully appreciate another culture, you must strive for constant, contemplative contact with that language. You must hear it, read it, read it aloud, savor it, study it, and appreciate it. And I think that computers and the Internet will play an expanding role in that ritual. 